Research Paper

\title{
Are three weeks hypofractionated radiation therapy (HFRT) comparable to six weeks for newly diagnosed glioblastoma patients? Results of a phase II study
}

\author{
Pierina Navarria ${ }^{1, *}$, Federico Pessina ${ }^{2, *}$, Stefano Tomatis $^{1}$, Riccardo Soffietti ${ }^{3}$, \\ Marco Grimaldi ${ }^{4}$, Egesta Lopci ${ }^{5}$, Arturo Chiti ${ }^{5,7}$, Antonella Leonetti ${ }^{9}$, Alessandra \\ Casarotti $^{2}$, Marco Rossi ${ }^{2}$, Luca Cozzi ${ }^{1}$, Anna Maria Ascolese ${ }^{1}$, Matteo Simonelli6,7, \\ Simona Marcheselli ${ }^{8}$, Armando Santoro ${ }^{6,7}$, Elena Clerici ${ }^{1}$, Lorenzo Bello ${ }^{2}$ and Marta \\ Scorsetti ${ }^{1,7}$ \\ ${ }^{1}$ Radiotherapy and Radiosurgery Department, Humanitas Cancer Center and Research Hospital, Rozzano, Italy \\ ${ }^{2}$ Neurosurgical Oncology Department, Humanitas Cancer Center and Research Hospital, Rozzano, Italy \\ ${ }^{3}$ Consultant of Neurosurgical Oncology Department, Humanitas Cancer Center and Research Hospital, Rozzano, Italy \\ ${ }^{4}$ Neuroradiology Unit, Radiology Department, Humanitas Cancer Center and Research Hospital, Rozzano, Italy \\ ${ }^{5}$ Nuclear Medicine Department, Humanitas Cancer Center and Research Hospital, Rozzano, Italy \\ ${ }^{6}$ Hematology and Oncology Department, Humanitas Cancer Center and Research Hospital, Rozzano, Italy \\ ${ }^{7}$ Department of Biomedical Sciences, Humanitas University, Rozzano, Italy \\ ${ }^{8}$ Department of Neurology, Humanitas Cancer Center and Research Hospital, Rozzano, Italy \\ ${ }^{9}$ Laboratory of Motor Control, Department of Medical Biotechnology and Translational Medicine, Milan University, Milan, Italy \\ *These authors have contributed equally to this work \\ Correspondence to: Pierina Navarria, email: pierina.navarria@humanitas.it \\ Keywords: glioblastoma, hypofractionated radiation therapy, temozolomide, phase II, surgery \\ Received: May 01,2017 Accepted: May 14, $2017 \quad$ Published: June 28, 2017 \\ Copyright: Navarria et al. This is an open-access article distributed under the terms of the Creative Commons Attribution License \\ 3.0 (CC BY 3.0), which permits unrestricted use, distribution, and reproduction in any medium, provided the original author and \\ source are credited.
}

\section{ABSTRACT}

Background: The current standard of care for newly diagnosed glioblastoma (GBM) is surgical resection, followed by radiation therapy (RT) with concurrent and adjuvant temozolomide chemotherapy (TMZ-CHT).. The patients outcome is still poor. In this study we evaluated hypofractionated radiation therapy (HFRT), instead of standard fractionated radiation therapy, with concomitant and adjuvant TMZ chemotherapy, in terms of safety and effectiveness.

Methods: Patients with newly diagnosed GBM, Karnofsky performance scale (KPS) $\geq 70$, and tumor up to $10 \mathrm{~cm}$ underwent maximal feasible surgical resection were treated. HFRT consisted of $60 \mathrm{~Gy}$, in daily fractions of $4 \mathrm{~Gy}$ given 5 days per week for 3 weeks. The primary endpoints were overall survival (OS), progression free survival (PFS), and incidence of radiation induced brain toxicity. Secondary endpoint was the evaluation of neurocognitive function.

Results: A total of 97 patients were included in this phase II study. The median age was 60.5 years (range 23-77 years). Debulking surgery was performed in $83.5 \%$ of patients, HFRT was completed in all 97 patients, concurrent and adjuvant TMZ in 93 (95.9\%). The median number of TMZ cycles was six (range 1-12 cycles). No severe toxicity occurred and the neuropsychological evaluation remained stable. At a median follow up time of 15.2 months the median OS time, 1,2-year OS rate were 15.9 months (95\% CI 14-18), $72.2 \%$ (95\% CI 62.1-80) and 30.4\% (95\% CI 20.8-40.6). Age, KPS, 


\section{MGMT methylation status, and extent of surgical resection were significant factors influencing the outcome. \\ Conclusion: HFRT with concomitant and adjuvant TMZ chemotherapy is an effective and safe treatment.}

\section{INTRODUCTION}

The standard of care for newly diagnosed glioblastoma multiforme (GBM) consists of surgical resection, followed by radiation therapy (RT) with concurrent and adjuvant temozolomide chemotherapy (TMZ-CHT). This approach affords a median overall survival (OS) time and a two years OS rate of 14.6 months and $26.5 \%$, respectively $[1,2]$. Although, the addition of CHT to RT has led to a survival advantage of two months on the average, the results are still unsatisfactory, and any improvement in this field is mandatory. Increasing evidence indicates that more extensive surgical resection, at least $\geq 80 \%$, is associated with a longer life expectancy, which become more prominent when the extent of resection (EOR) reaches $95 \%-100 \%$ of the tumor contrast enhancement area $[3,4]$. To date, all the attempts to enhance the efficacy of RT were unsuccessful. Dose escalation up to 90 Gy using conventional fractionation or stereotactic radiosurgery boost did not lead to any improvement in outcome, and in most series local recurrence occurred within the high-dose regions [5-10]. The impact of hypofractionated radiation therapy (HFRT) has been investigated as well. The delivery of a higher dose per fraction over a shorter time frame has the advantages to achieve an increase in cells killing and a reduction in accelerated tumor cell repopulation. The initial experiences were carried out in elderly and frail patients with the aim to reduce the overall treatment time in this poor-prognosis subgroup [11-13]. The patients outcome were equivalent to conventional fractionation, although a lower total doses were used. More recently, HFRT has been employed in newly diagnosed GBM patients with a curative aim [14-18]. Retrospective and prospective studies showed that this approach shares similar feasibility and safety results as standard RT schemes, without a growing incidence of neurological toxicity. Nowadays, the impact of HFRT should be investigated in the setting of a multimodality approach which combines concurrent CHT and RT. Consequently, we designed a prospective phase II trial consisting of postoperative HFRT with concurrent and adjuvant TMZ-CHT, following surgical resection, to explore the impact of HFRT on GBM outcome in the modern era. Primary endpoints of the study were overall survival (OS), progression free survival (PFS), and incidence of radiation induced brain toxicity. Secondary endpoint was the evaluation of neurocognitive function.

\section{RESULTS}

\section{Patients and treatments}

From August 2013 to December 2015, out of 125 HGG patients enrolled into the trial, 97 were newly diagnosed GBM. Patients and tumor characteristics are shown in Table 1. Debulking surgery was performed in $80(82.5 \%)$ patients and biopsy in $17(17.5 \%)$. HFRT was carried out in all 97 patients. Concurrent and adjuvant TMZ was performed in $93(95.9 \%)$ patients and omitted in $4(4.1 \%)$ for liver disorders, pulmonary distress, or hematologic toxicity. Characteristics and intensity of treatments are detailed in Table 2. The median follow up time for the whole cohort was 15.2 months (range 3.2-36.8) and 20.2 months (13.1-36.8) for the alive patients.

\section{Progression free survival (PFS) and overall survival analyses}

The median OS time, and the 1, 2-year OS rate were 15.9 months (95\% CI 14.8-18.2), $72.2 \%$ (95\% CI 62.1-80) and $30.4 \%(95 \% \mathrm{CI} 20.8-40.6)$ as shown in Figure 1. At the last observation time, 29 (29.9\%) patients are alive and $68(70.1 \%)$ dead. The median PFS time, and the 1 , 2-year PFS rate were 10.9 months (95\% CI 9.6-12.5), $42.3 \%$ (95\% CI 32.4-51.8), and $15.2 \%$ (95\% CI 8.2-24.0), respectively as shown in Figure 2.

\section{Prognostic factors analyses}

Survival according to prognostic factors, including age, gender, KPS, MGMT status, EOR, target volume, and number of adjuvant TMZ cycles, was analyzed as well. The highest benefit was observed in treated patients with age $\leq 60$ years, KPS 100, and RPA class 3 . Details are shown in Table 3.

\section{Postoperative assessment}

No mortality or major peri-operative morbidity occurred. Postoperative new neurological deficits were observed in eight (8.2\%) patients, in two cases recovered during RT treatment; they consisted in motor deficit in three, hemianopsia in two, aphasia in two, and motor deficit plus hemianopsia in one patient. 
Table 1: Patients and tumor characteristics

\begin{tabular}{|c|c|c|}
\hline & $\mathbf{n}$ & $\%$ \\
\hline Patients & 97 & 100 \\
\hline \multicolumn{3}{|l|}{ Gender } \\
\hline Female & 36 & 37 \\
\hline Male & 61 & 63 \\
\hline \multicolumn{3}{|l|}{ Age (years) } \\
\hline Median (range years) & $61(23-74)$ & \\
\hline$\leq 60$ & 49 & 51 \\
\hline $61-70$ & 34 & 35 \\
\hline$>70$ & 14 & 14 \\
\hline \multicolumn{3}{|l|}{ KPS } \\
\hline 70 & 6 & 6 \\
\hline 80 & 25 & 26 \\
\hline 90 & 35 & 36 \\
\hline 100 & 31 & 32 \\
\hline \multicolumn{3}{|l|}{ RPA } \\
\hline III & 8 & 8 \\
\hline IV & 13 & 14 \\
\hline $\mathrm{V}$ & 76 & 78 \\
\hline \multicolumn{3}{|l|}{ Tumor molecular profile } \\
\hline IDH wild type & 97 & 100 \\
\hline MGMT methylated & 61 & 63 \\
\hline MGMT unmethylated & 36 & 37 \\
\hline \multicolumn{3}{|l|}{ Number of cerebral lobes involved } \\
\hline 1 lobe & 56 & 58 \\
\hline 2 lobes & 30 & 31 \\
\hline 3 lobes & 5 & 5 \\
\hline Multifocal tumor & 6 & 6 \\
\hline \multicolumn{3}{|l|}{ Median Volumes treated $\mathrm{cm}^{3}$ (range $\mathrm{cm}^{3}$ ) } \\
\hline CTV1 & \multicolumn{2}{|c|}{$79(11-197)$} \\
\hline PTV1 & \multicolumn{2}{|c|}{$166(34-401)$} \\
\hline CTV2 & \multicolumn{2}{|c|}{$127(11-321)$} \\
\hline PTV2 & \multicolumn{2}{|c|}{$241(34-510)$} \\
\hline Median max SUV [11C]METPET before HFRT & \multicolumn{2}{|c|}{$3 \cdot 6(0-8 \cdot 1)$} \\
\hline
\end{tabular}

KPS=Karnofsky performance scale; $\mathrm{RPA}=$ recursive partitioning analysis; $\mathrm{IDH} 1=$ isocitrate dehydrogenase; $\mathrm{MGMT}=\mathrm{O}$ 6-methylguanine-DNA methyltransferase; $\mathrm{CTV}=$ clinical target volume; $\mathrm{PTV}=$ planning target volume; HFRT= hypofractionated radiation therapy; SUV [11C]METPET= 11 carbonione Methionine-Positron Emission Tomography 
Table 2: Characteristics and intensity of treatments

\begin{tabular}{|c|c|c|}
\hline Variables & n. & $\%$ \\
\hline Surgery: & 97 & 100 \\
\hline GTR & 53 & 55 \\
\hline STR & 15 & 15 \\
\hline PR & 12 & 12 \\
\hline Biopsy & 17 & 17 \\
\hline HFRT: & 97 & 100 \\
\hline \multicolumn{3}{|l|}{ Total doses/dose per fraction Gy } \\
\hline PTV1 & $60 / 4$ & 100 \\
\hline PTV2 & $42 / 2 \cdot 8$ & 100 \\
\hline Number of fractions & 15 & 100 \\
\hline Interruption & 0 & 0 \\
\hline Median duration weeks (range weeks) & & $3(2.6-4.1)$ \\
\hline \multicolumn{3}{|l|}{ Chemotheraphy: } \\
\hline Concomitant temozolomide & 93 & 96 \\
\hline Never started concomitant temozolomide & 4 & 4 \\
\hline \multicolumn{3}{|l|}{ Reasons } \\
\hline Liver disfunction & 2 & 2 \\
\hline Pulmonary distress & 1 & 1 \\
\hline Hematologic disorder & 1 & 1 \\
\hline Adjuvant temozolomide & 93 & 96 \\
\hline Never started adjuvant temozolomide & 4 & 4 \\
\hline \multicolumn{3}{|l|}{ Reasons } \\
\hline Hematologic toxicity & 2 & 2 \\
\hline Liver disfunction & 2 & 2 \\
\hline Median number of cycles (range) & & $6(0-12)$ \\
\hline
\end{tabular}

GTR=gross total resection: $<1 \mathrm{~cm} 3$ of residual tumor volume; $\mathrm{STR}=$ subtotal resection:1-10cm 3 of residual tumor volume; $\mathrm{PR}=$ partial resection: $>10 \mathrm{~cm} 3$ of residual tumor volume; HFRT= hypofractionated radiation therapy; $\mathrm{PTV}=\mathrm{planning}$ target volume

\section{CHT-HFRT side effects}

All patients completed the scheduled HFRT plan; a transient neurological deterioration was recorded in two patients, consisting of partial seizure and aphasia. Grade I-II radionecrosis (RN) occurred in $22(22.7 \%)$ patients. No Grade III- IV radionecrosis were observed. Fatigue was observed in $55(56.7 \%)$ patients during concurrent CHT-HFRT. Grade 2-4 hematologic toxicity was recorded in $12(12.9 \%)$ patients, in three during concomitant treatment and in nine patients during adjuvant TMZ. No thromboembolic events or cerebral hemorrhage occurred.

\section{Neuropsychological evaluation}

1Neuropsychological scores before and after HFRT remained unchanged. The analysis showed no detrimental effect of HFRT on cognitive functions (language, short and long term verbal and visuo-spatial memory, working memory, attentive and executive functions). Particularly, a significant performance improvement was detected: between T0 and $\mathrm{T} 1$ in the copy of the figure test ( $\mathrm{p}$ value $<<0.01$ ), in the recall of the complex figure tests ( $p$ value $<<0.01)$, in the ideomotor apraxia test $(\mathrm{p}=0.03)$, and in the trail making test part A ( $\mathrm{p}$ value $=0.04$ ); between $\mathrm{T} 1$ 
and $\mathrm{T} 2$ in the ideomotor apraxia test $(\mathrm{p}$ value $=0.02)$ and in the trail making test part B-A ( $\mathrm{p}$ value $=0.01)$ (Table 4).

\section{Treatment at progression}

Brain progression occurred in $77(79.4 \%)$ patients and a salvage treatment was performed in 34 (44.2\%). It consisted in surgery alone in one, radiation therapy alone in one, surgery with sequential chemo-radiotherapy in five and second line chemotherapy alone in 26. The chemotherapeutic agents more frequently used were fotemustine and temozolomide. The median survival time from progression was 8.5 months (95\% CI 5.4-11.4).

\section{DISCUSSION}

Based on the results of the phase III EORTC-NCIC trial, the current standard treatment for newly diagnosed GBM patients consists of radiotherapy with concomitant and adjuvant TMZ-CHT [1]. Fractionated conformal threedimensional radiotherapy (3DCRT) to a total dose of 60 Gy in 30 daily fractions of 2 Gy each is employed based on the results from previous dose exploratory studies [19]. The use of protracted RT schedules harbors the theoretical drawback of allowing a cell repopulation, which could be of relevance in tumors with a rapid doubling time such as GBM [20]. This effect may be seen in routine clinical practice as well, where a widely rate of patients, up to $10 \%$, discontinues RT for disease progression [1]. Hypofractionated radiation therapy (HFRT) offers the advantages of achieving an increased cells killing action, by the delivery of a higher dose per fraction over a shorter time frame, and of reducing the effect of accelerated tumor cell repopulation by shrinking the RT treatment time. Based on these observations, we designed this phase II study to assess the feasibility and the effectiveness of HFRT schedule within a multimodal therapeutic approach, including concurrent and adjuvant TMZ-CHT, following surgical resection. Although the initial study design included all grade of $\mathrm{HGG}$, we report here the analysis of the newly diagnosed IDH wild type GBM patients only, to deal with a highly homogeneous population. To now, few data are available in GBM patients on the impact of HFRT used to radical doses into a multimodal strategy including surgery, concomitant and adjuvant chemotherapy [14-18]. The published studies are often phase I investigation, with a limited number of cases treated, quite heterogeneous for patients and tumors characteristics. However, the preliminary results were promising, with a median OS up to 20 months in some series, and with a low incidence of symptomatic radionecrosis or severe neurologic side effects. Table 5 showed some of the most relevant phase

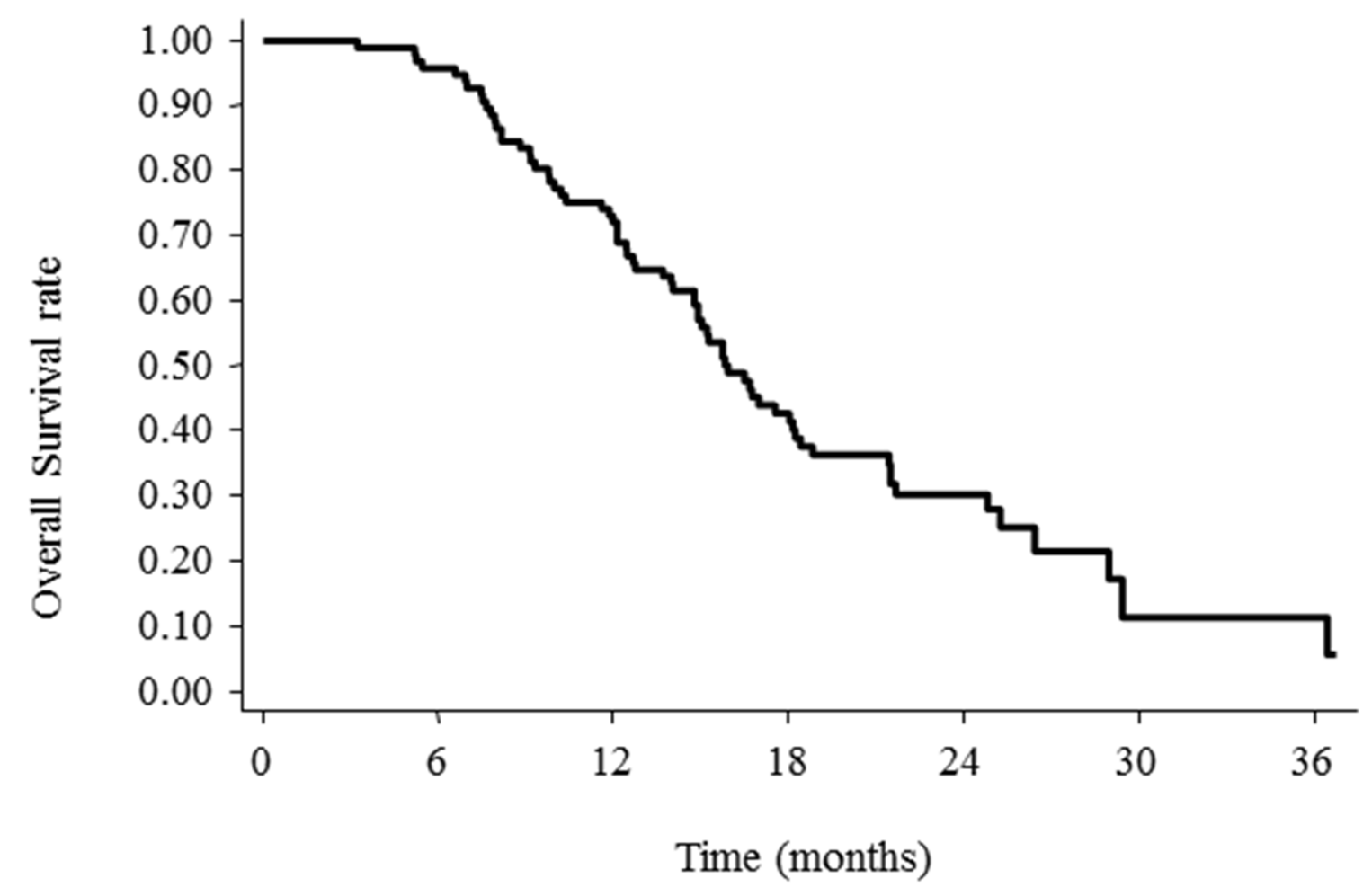
n. at risk:
97
93
70
34
17
2
2

Figure 1: Overall survival for GBM cases treated with hypofractionated radiotherapy with concurrent and adjuvant temozolomide chemotherapy following any entity of surgical resection. 
I-II studies about this issue. There is no agreement about the optimal HFRT doses to deliver and the schedule to employ. With the aim to improve the impact on outcome, a therapeutic effective dose greater than that of conventional radiotherapy $\left(\mathrm{BED}_{10} 84 \mathrm{~Gy}\right.$ vs $\left.72 \mathrm{~Gy}\right)$ was applied. Our results compare favorably with previous reports regarding standard RT treatment [1], with a median OS time, 1, 2-year OS rate of 15.8 months, $72.2 \%$ and $28.5 \%$, and a median PFS time, 1, 2-year PFS rate of 10.8 months, $42.3 \%$ and $16 \%$, respectively, as shown in Table 6. Employing this approach, notwithstanding a higher dose on large tumor volume was delivered, all patients completed HFRT treatment, no neurological deterioration was observed and neurocognitive functions remained stable or in some cases improved, as shown by neuropsychological evaluation. Published data suggest an increased incidence of grade III-IV radionecrosis when a high dose per fraction and therapeutic effective doses are used, ranging from $3 \%$ to $20 \%$ according to the various scheme utilized [21, 22]. In our analysis only grade I-II toxicity was recorded and in no patients grade III-IV was detected. Several prognostic factors were investigated. As in many other published studies, in our series age was a factor strongly influencing survival $(p=0.01)$. The greater benefit of treatment was observed in patients younger than 60 years, with a percentage of $40 \%$ alive at two years.
Along with age, KPS was found to significantly affect outcome as well, with more than $50 \%$ of patients with KPS 100 surviving beyond two years $(\mathrm{p}=<<0.01)$. The extent of surgical resection has been commonly considered as a factor affecting outcome in GBM patients [3, 4, 23]. Different methodologies to define the amount of tumor removal have been used. In our study, we defined three groups of patients in relation to the RTV. A favorable trend was observed in case of RTV $<10 \mathrm{~cm}^{3}$ that was obtained in about $70 \%$ of patients $(\mathrm{p}=0.03)$. Although an extensive surgical resection was performed in the largest number of patients treated, no major perioperative morbidity occurred and adjuvant treatments was started without delays. Literature data proved that postoperative neurological functions are crucial elements for patient quality of life (QoL) and OS. As reported by McGirt et al, new motor or language deficits are associated with significant decreases in the median survival of patients with GBM supporting the need of coupling maximal tumor resection with preservation of neurological integrity [24]. Considering the small size of RTV and the absence of major neurological deficit, no increase in corticosteroid drugs or AED dosage was needed during concomitant chemo-radiotherapy, and the HFRT was well tolerated along all treatment period. One might speculate that a radiotherapy intensification jeopardizes the patient ability of completing an adequate

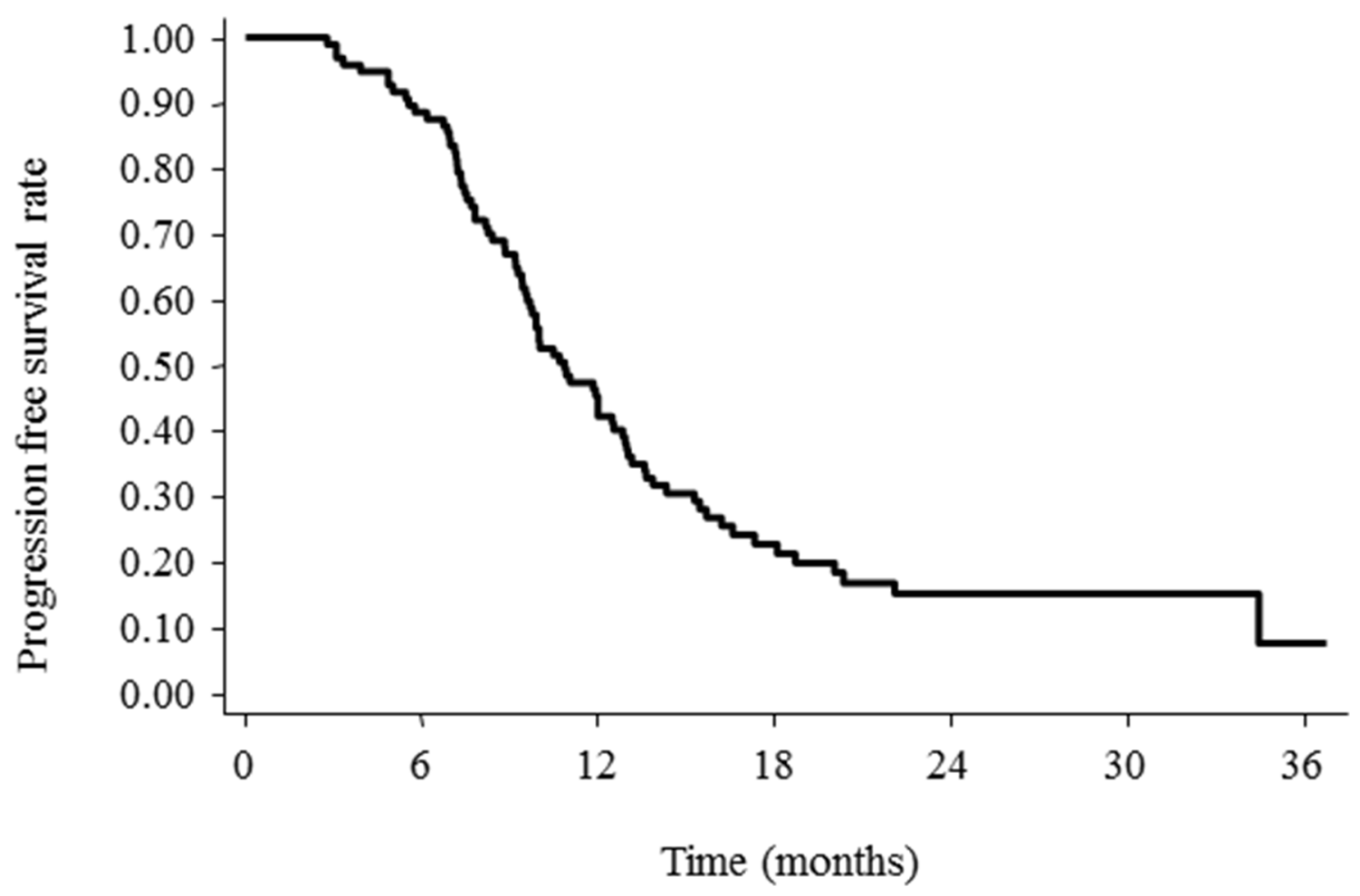
n. at risk:
97
86
41
16
7
2
1

Figure 2: Progression Free Survival (PFS) for GBM cases treated with hypofractionated radiotherapy followed any entity of surgical resection. 
Table 3: Kaplan-Meyer overall survival according to subgroup analyses

\begin{tabular}{|c|c|c|c|c|c|c|c|}
\hline & Patients & $\begin{array}{c}\text { Median } \\
\text { OS months } \\
\text { (months } \\
\mathbf{9 5 \% C I )}\end{array}$ & $\begin{array}{c}\text { 1-year OS } \\
(95 \% \mathrm{CI})\end{array}$ & $\begin{array}{c}\text { 2-year OS } \\
(95 \% \mathrm{CI})\end{array}$ & $\begin{array}{l}\text { p value } \\
\text { univariate }\end{array}$ & $\begin{array}{c}\text { HR } \\
\text { multivariate } \\
(95 \% \mathrm{CI})\end{array}$ & $\begin{array}{c}\text { p value } \\
\text { multivariate }\end{array}$ \\
\hline $\begin{array}{l}\text { Overall } \\
\text { survival }\end{array}$ & 97 & $15.9(14.8-18.2)$ & $72.2(62.1-80)$ & $30.4(20.8-40.6)$ & & & \\
\hline \multicolumn{8}{|l|}{ Gender } \\
\hline Female & 36 & $15.2(10-18.2)$ & $58.3(40.7-72.4)$ & $23.2(10.5-38.8)$ & 0.24 & 0.78 & 0.36 \\
\hline Male & 61 & $16.7(14.8-21.7)$ & $80.3(68-88.3)$ & $34.5(21.6-47.7)$ & & & \\
\hline \multicolumn{8}{|l|}{ Age } \\
\hline$\leq 60$ & 49 & $18.4(14.9-24.8)$ & $79.6(65.4-88.5)$ & $37.3(23-51.7)$ & 0.03 & 1.39 & 0.28 \\
\hline$>60$ & 48 & $14.9(12-16.7)$ & $64.6(49.4-76.3)$ & $23.2(11.5-37.2)$ & & & \\
\hline \multicolumn{8}{|l|}{ KPS } \\
\hline 70 & 6 & 9.1 (7.9-ne) & $33.3(4.6-67.6)$ & 0 & $<<0.01$ & 0.95 & $<0.01$ \\
\hline 80 & 25 & $12.7(10-15.8)$ & $68(46.1-82.5)$ & $13(2.7-31.8)$ & & & \\
\hline 90 & 35 & $14.9(12-16.5)$ & $65.7(47.6-78.9)$ & $24(11.1-39.7)$ & & & \\
\hline 100 & 31 & 25.2 (18.4-ne) & $90.3(72.9-96.8)$ & $56.9(35.2-73.7)$ & & & \\
\hline \multicolumn{8}{|l|}{ RPA } \\
\hline III & 8 & $\mathrm{nr}$ & 100 & $68.6(21.3-91.2)$ & 0.02 & 1.35 & 0.30 \\
\hline IV & 13 & 15.2 (9.1-ne) & $76.9(44.2-91.9)$ & $26(6.3-51.7)$ & & & \\
\hline $\mathrm{V}$ & 76 & $15.7(12.7-18)$ & $69.3(57.6-78.4)$ & $27.5(17-38.9)$ & & & \\
\hline \multicolumn{8}{|l|}{ EOR } \\
\hline GTR & 53 & $17(15.2-21.4)$ & $81.1(67.8-89.4)$ & $31.4(18.1-45.6)$ & 0.13 & 1.27 & 0.04 \\
\hline STR & 15 & $15.9(9.8-26.4)$ & $73.3(43.6-89.1)$ & $35.6(12.1-60.3)$ & & & \\
\hline PR & 12 & $14.8(8.8-21.5)$ & 75 (40.9-91.2) & $13.9(0.9-44.1)$ & & & \\
\hline Biopsy & 17 & 9.3 (7-ne) & $41.2(18.6-62.6)$ & $29.4(10.7-51.2)$ & & & \\
\hline \multicolumn{8}{|l|}{ MGMT } \\
\hline Methylated & 61 & $18(14.8-21.7)$ & $75.4(62.6-84.4)$ & $35.4(22.7-48.4)$ & 0.07 & 0.58 & 0.04 \\
\hline Unmethylated & 36 & $14.9(11.8-16.7)$ & $66.7(48.8-79.5)$ & $21.8(9.1-38.1)$ & & & \\
\hline
\end{tabular}

$\mathrm{KPS}=$ Karnofsky performance scale; RPA=recursive partitioning analysis; $\mathrm{EOR}=$ extent of resection;

$\mathrm{GTR}=$ gross total resection: $<1 \mathrm{~cm} 3$ of residual tumor volume; $\mathrm{STR}=$ subtotal resection: $1-10 \mathrm{~cm} 3$ of residual tumor volume; $\mathrm{PR}=$ partial resection: $>10 \mathrm{~cm} 3$ of residual tumor volume; $\mathrm{MGMT}=\mathrm{O}-6$-methylguanine-DNA methyltransferase; $\mathrm{nr}=\mathrm{not}$ reached; ne=not evaluable.

adjuvant chemotherapy treatment. In our cohort, TMZ was successfully administered to $96 \%$ of patients, and more than $50 \%$ of them received more than 6 cycles. In addition, salvage treatment at progression was done in about $45 \%$ of patients and the median survival of patients was 8.5 months, clearly higher respect to other series [1, $2]$. We are aware that our study does not reach the power of a randomized trial in terms of sample size and longer follow up time. Nevertheless, the results shown indicates that HFRT is a feasible and safe approach, affording good survival rates, and considerable decrease in the treatment time (from 6 to 3 weeks), which could be relevant in a group with short life expectancy, such as GBM patients. Subjects who had the greatest benefit are those with young age, good performance status, maximal safe resection, and a MGMT methylated tumor. Open questions remain the optimal radiation total doses to deliver and the schedule to utilize, but HFRT within a multimodal therapeutic approach, seems a way forward to improve the outcome of patients with glioblastoma. 
Table 4: Neuropsychological outcome

\begin{tabular}{|c|c|c|c|c|c|c|c|c|c|c|c|c|}
\hline \multirow{3}{*}{$\begin{array}{l}\text { Cognitive } \\
\text { domains }\end{array}$} & \multirow[t]{3}{*}{ Test } & \multirow{2}{*}{\multicolumn{2}{|c|}{$\begin{array}{c}\text { T0 } \\
\text { Before } \\
\text { HFRT }\end{array}$}} & \multicolumn{3}{|c|}{ T1 } & \multicolumn{3}{|c|}{$\mathbf{T 2}$} & \multicolumn{3}{|c|}{ T3 } \\
\hline & & & & \multicolumn{3}{|c|}{1 month after HFRT } & \multicolumn{3}{|c|}{$\begin{array}{c}6 \text { months after } \\
\text { HFRT }\end{array}$} & \multicolumn{3}{|c|}{$\begin{array}{c}12 \text { months after } \\
\text { HFRT }\end{array}$} \\
\hline & & n. & mean & n. & mean & $\begin{array}{l}\text { p value } \\
\text { (T0-T1) }\end{array}$ & n. & mean & $\begin{array}{l}\text { p value } \\
\text { (T0-T2) }\end{array}$ & n. & mean & $\begin{array}{l}\text { p value } \\
\text { (T0-T3) }\end{array}$ \\
\hline \multirow[t]{4}{*}{ Language } & Token & 85 & 29.1 & 80 & 29.7 & 0.1 & 33 & 28.5 & 0.2 & 12 & 28.5 & 0.50 \\
\hline & Picture Naming & 85 & 42.2 & 85 & 43.7 & 0.07 & 33 & 43.5 & 0.43 & 12 & 42.9 & 0.71 \\
\hline & Fonological fluency & 75 & 20.5 & 73 & 22.6 & 0.12 & 31 & 20.3 & 1.0 & 11 & 20.2 & 0.95 \\
\hline & Semantic Fluency & 74 & 29.7 & 73 & 32.6 & $0.05 *$ & 31 & 32.1 & 0.13 & 11 & 32.7 & 0.21 \\
\hline \multirow[t]{7}{*}{ Memory } & Digit span forward & 85 & 5.0 & 79 & 5.1 & 0.31 & 32 & 4.9 & 0.68 & 11 & 4.8 & 1.00 \\
\hline & Corsi span forward & 85 & 4.0 & 80 & 4.1 & 0.22 & 34 & 4.3 & 0.18 & 11 & 4.0 & 0.75 \\
\hline & $\begin{array}{l}\text { Digit span } \\
\text { backward }\end{array}$ & 85 & 3.2 & 79 & 3.4 & 0.14 & 33 & 3.5 & 0.93 & 11 & 3.4 & 0.63 \\
\hline & $\begin{array}{l}\text { Corsi span } \\
\text { backward }\end{array}$ & 84 & 3.5 & 80 & 3.7 & 0.11 & 32 & 3.7 & 0.80 & 12 & 3.4 & 0.45 \\
\hline & $\begin{array}{l}\text { Rey's } 15 \text { words test } \\
\text { - immediate }\end{array}$ & 72 & 29.7 & 67 & 30.4 & 0.42 & 29 & 29.8 & 0.32 & 11 & 31.8 & 0.29 \\
\hline & $\begin{array}{l}\text { Rey's } 15 \text { words test } \\
\text { - delayed }\end{array}$ & 72 & 5.0 & 66 & 5.1 & 0.96 & 28 & 5.1 & 0.53 & 11 & 5.5 & 0.55 \\
\hline & $\begin{array}{l}\text { Recall complex } \\
\text { figure }\end{array}$ & 78 & 9.8 & 78 & 12.0 & $<<0.01 *$ & 32 & 13.4 & 0.01 & 12 & 12.9 & 0.20 \\
\hline $\begin{array}{l}\text { Visuo- } \\
\text { constuctional } \\
\text { abilities }\end{array}$ & Copy of the figure & 78 & 25.7 & 78 & 28.1 & $<<0.01 *$ & 31 & 27.7 & 0.49 & 12 & 29.3 & 0.24 \\
\hline \multirow[t]{2}{*}{ Apraxia } & Ideomotor apraxia & 85 & 66.0 & 79 & 66.2 & $0.03 *$ & 31 & 67.4 & $0.02 *$ & 12 & 56.2 & 0.33 \\
\hline & Orofacial apraxia & 84 & 19.2 & 78 & 19.4 & 0.16 & 31 & 19.3 & 0.30 & 12 & 19.2 & 0.32 \\
\hline \multirow{7}{*}{$\begin{array}{l}\text { Attention } \\
\text { and executive } \\
\text { functions }\end{array}$} & $\begin{array}{l}\text { Trail Making test } \\
-\mathrm{a}\end{array}$ & 34 & 54.9 & 38 & 50.1 & $0.04 *$ & 23 & 52.7 & 0.78 & 8 & 44.6 & 0.32 \\
\hline & $\begin{array}{l}\text { Trail Making test } \\
-\mathrm{b}\end{array}$ & 31 & 169.8 & 37 & 168.8 & 0.08 & 21 & 157.8 & 0.06 & 6 & 150.2 & 0.18 \\
\hline & $\begin{array}{l}\text { Trail Making test } \\
-\mathrm{b}-\mathrm{a}\end{array}$ & 31 & 114.8 & 37 & 123.5 & 0.26 & 21 & 105.9 & $0.01 *$ & 6 & 108.1 & 0.18 \\
\hline & Attentive matrices & 84 & 41.3 & 80 & 41.6 & 0.37 & 33 & 40.7 & 0.70 & 12 & 37.4 & 0.08 \\
\hline & Stroop Test - error & 70 & 2.0 & 72 & 1.2 & 0.30 & 28 & 1.8 & 0.62 & 10 & 2.9 & 0.95 \\
\hline & Stroop Test - time & 70 & 28.7 & 72 & 28.9 & 0.56 & 28 & 35.1 & 0.71 & 10 & 52.3 & 0.41 \\
\hline & $\begin{array}{l}\text { Raven coulored } \\
\text { progressive } \\
\text { matrices }\end{array}$ & 80 & 26.3 & 74 & 27.2 & 0.24 & 31 & 27.6 & 0.22 & 10 & 29.1 & 0.47 \\
\hline
\end{tabular}

HFRT=hypofractionated radiation therapy; $\mathrm{N}=$ number of patients; mean= age-education-adjusted score for each test and for each time point;

T0: before HFRT; T1:1 month after HFRT; T2:6 months after HFRT; T3:12 months after HFRT; * significant p values $(\mathrm{p} \leq 0 \cdot 05)$ 
Table 5: Published studies regarding hypofractionated radiation therapy

\begin{tabular}{|c|c|c|c|c|c|c|c|c|c|}
\hline Authors & N pts & Study design & $\begin{array}{c}\text { Concurrent } \\
\text { and adjuvant } \\
\text { TMZ }\end{array}$ & Total dose & $\mathrm{N}$ frs & $\mathbf{R N}$ & Median OS & $\begin{array}{l}1 \text { year } \\
\text { OS \% }\end{array}$ & $\begin{array}{c}2 \text { years } \\
\text { OS } \%\end{array}$ \\
\hline Chen (14) & 16 & Phase I & yes & $60 \mathrm{~Gy}$ & $\begin{array}{l}20 \\
15 \\
12 \\
10\end{array}$ & $\begin{array}{l}1 \mathrm{G} 4 \\
3 \mathrm{G} 3\end{array}$ & 16.3 months & $\mathrm{nr}$ & $\mathrm{nr}$ \\
\hline Terasaky (16) & 26 & Pilot & yes & 45 Gy & 15 & no & 15.6 months & $\mathrm{nr}$ & $\mathrm{nr}$ \\
\hline Reddy (15) & 24 & Phase II & yes & $\begin{array}{l}60 \mathrm{~Gy} \\
30 \mathrm{~Gy}\end{array}$ & $\begin{array}{l}10 \\
10\end{array}$ & no & 16.6 months & $\mathrm{nr}$ & $\mathrm{nr}$ \\
\hline Jastaniyah (17) & 25 & Phase I & yes & $60 \mathrm{~Gy}$ & 22 & no & 15.7 months & 62 & 9 \\
\hline Iuchi (18) & 46 & Phase II & yes & $\begin{array}{l}68 \mathrm{~Gy} \\
40 \mathrm{~Gy} \\
32 \mathrm{~Gy}\end{array}$ & $\begin{array}{l}8 \\
8 \\
8\end{array}$ & $\begin{array}{l}20 \\
\text { G3 }\end{array}$ & 20 months & 50 & 41 \\
\hline
\end{tabular}

Pts=patients; $\mathrm{TMZ}=$ temozolomide; frs=fractions; $\mathrm{RN}=$ radionecrosis; $\mathrm{OS}=$ overall survival; no=not observed; $\mathrm{nr}=\mathrm{not}$ reported

Table 6: comparison between standard (6 weeks) radiation therapy (Stupp et al. [1]) and hypofractionated (3 weeks) radiation therapy within multimodal approach

\begin{tabular}{|c|c|c|c|c|}
\hline \multirow{2}{*}{$\begin{array}{l}\text { Variables } \\
\text { Extent of surgery }\end{array}$} & \multicolumn{2}{|c|}{$\begin{array}{c}\text { Concurrent and adjuvant TMZ CHT } \\
\text { with standard RT } \\
(60 \mathrm{~Gy} \text { in } 30 \text { fractions })\end{array}$} & \multicolumn{2}{|c|}{$\begin{array}{c}\text { Concurrent and adjuvant TMZ CHT } \\
\text { with hypofractionated RT } \\
\text { (60 Gy in } 15 \text { fractions) }\end{array}$} \\
\hline & & & & \\
\hline Biopsy & \multicolumn{2}{|c|}{$17 \%$} & \multicolumn{2}{|c|}{$17.5 \%$} \\
\hline Debulking & \multicolumn{2}{|c|}{$83 \%$} & \multicolumn{2}{|c|}{$82.5 \%$} \\
\hline \multicolumn{5}{|l|}{ Radiotherapy } \\
\hline Never started & \multicolumn{2}{|c|}{$1 \%$} & \multicolumn{2}{|c|}{$0 \%$} \\
\hline Early discontinuation* & \multicolumn{2}{|c|}{$10 \%$} & \multicolumn{2}{|c|}{$0 \%$} \\
\hline \multicolumn{5}{|l|}{ Concurrent TMZ CHT } \\
\hline Never started & \multicolumn{2}{|c|}{$2 \%$} & \multicolumn{2}{|c|}{$4.1 \%$} \\
\hline \multicolumn{5}{|l|}{ Adjuvant TMZ CHT } \\
\hline Never started & \multicolumn{2}{|c|}{$22 \%$} & \multicolumn{2}{|c|}{$4 \%$} \\
\hline $\begin{array}{l}\text { Number of median } \\
\text { cycles (range) }\end{array}$ & \multicolumn{2}{|c|}{$3(0-7)$} & \multicolumn{2}{|c|}{$6(0-12)$} \\
\hline$P F S$ & \multicolumn{2}{|c|}{$(95 \% \mathrm{CI})$} & \multicolumn{2}{|c|}{$(95 \% \mathrm{CI})$} \\
\hline Median & 6.9 months & $(5.8-8.2)$ & 10.9 months & $(9.6-12.5)$ \\
\hline 1year & $26.9 \%$ & $(21.8-32.1)$ & $42.3 \%$ & $(32.4-51.8)$ \\
\hline 2 year & $10.7 \%$ & $(7.0-14.3)$ & $15.2 \%$ & $(8.2-24.0)$ \\
\hline \multicolumn{5}{|l|}{ OS } \\
\hline Median & 14.6 months & $(13.2-16-8)$ & 15.9 months & $(14.8-18.2)$ \\
\hline 1 year & $61.1 \%$ & $(55.4-66.7)$ & $72.2 \%$ & $(62.1-80)$ \\
\hline 2 year & $26.5 \%$ & $(21.2-31.7)$ & $30.4 \%$ & $(20.8-40.6)$ \\
\hline
\end{tabular}

*for disease progression

$\mathrm{TMZ}=$ temozolomide; $\mathrm{CHT}=$ chemotherapy; $\mathrm{PFS}=$ progression free survival; $\mathrm{OS}=$ overall survival 


\section{MATERIALS AND METHODS}

\section{Study design and patients}

The present trial was a prospective single arm phase II study approved by our institutional review board. The trial was registered at ClinicalTrials.gov site with number NCT00006353. All patients provided a written informed consent to the treatment and the use of their data for scientific purposes. Eligible patients had: 1) an age of 18-70 years and a Karnofsky performance scale (KPS) $\geq 60 ; 2$ ) a newly diagnosed high grade gliomas (HGG); 3 ) a residual tumor or surgical cavity with a maximum diameter of $10 \mathrm{~cm}$; 4) a normal liver, kidney and bone marrow functions. A limited number of patients older than 70 years with KPS $\geq 80$ were included as well. We report here the analysis of GBM patient population group only.

\section{Procedures}

\section{Surgery}

Surgery was performed in all patients with the aim to maximally remove the tumor according to functional boundaries. Tumor removal was achieved with the aid of brain mapping techniques and imaging neuro-navigation (post contrast T1 weighted images, MET-PET, FLAIR, functional MRI, DTI) coupled with intraoperative ultrasounds, to afford maximal resection and maintenance of full patient functional integrity. Extent of resection (EOR) was determined by comparing preoperative postcontrast T1 weighted MRI with postoperative MRI study, acquired within 48 hours after surgery, and calculated as follows: preoperative tumor volume - postoperative tumour volume/preoperative tumor volume. Gross total resection (GTR) was defined as residual tumor volume (RTV) lower than $1 \mathrm{~cm}^{3}$, subtotal resection (STR) when RTV was among 1 and $10 \mathrm{~cm}^{3}$, and partial resection (PR) when it was greater than $10 \mathrm{~cm}^{3}$ [25]. Patients who received biopsy only were also enrolled. Tumor molecular profile was available in all cases. Immunohistochemical staining for Isocitrate dehydrogenase (IDH1/2) was performed on BenchMark XT automated tissue staining systems (Ventana Medical Systems, Inc., Tucson, AZ) using validated protocols. O-6-methylguanine-DNA methyltransferase (MGMT) promoter methylation status was determined by pyrosequencing (Diatech Pharmacogenetics, MGMT plus, valid CE/IVD) [26].

\section{Hypofractionated radiation therapy (HFRT)}

CT scan, T1-weighted FLAIR (fluid-attenuated inversion recovery images) and T2-weighted 3D-FLAIR followed by T1-weighted MPRAGE MRI and [11C]Methionine-PET (11CMETPET) were acquired for radiation therapy planning and images were co-registered each other. Pre and post-operative MRI acquired within 48 hours from surgery were used too to better define the target RT volume. Two different clinical target volume (CTV) were outlined: CTV1 corresponded to the entire surgical cavity plus eventual residual tumor after surgery or, to the abnormality on the T1-weighted post-contrast MPRAGE and 11CMETPET in case of biopsy; CTV2 corresponded to the abnormality on FLAIR MRI images before surgery. Planning target volume 1-2 (PTV1/PTV2) was generated adding an isotropic margin of $5 \mathrm{~mm}$ from CTV1 and CTV2 respectively. Intensity modulated radiation therapy was performed within 4-6 weeks after surgery using volumetric modulated arc therapy (VMAT). The dose prescribed was 60 Gy with daily fraction of 4 Gy on PTV1, and 42 Gy with daily fraction of 2.8 Gy on PTV2 for 15 consecutive days, using a simultaneous integrated boost (SIB). Organs at risk (OARs) outlined were optic nerves and chiasm, lens, brainstem and cochlea without additional margins, and the recommended maximal doses were $\leq 40 \mathrm{~Gy}, \leq 10 \mathrm{~Gy}, \leq 30 \mathrm{~Gy}$, and $\leq 30$ Gy, respectively. Dose was prescribed to an isodose line that ensured that more than $98 \%$ of PTV1-2 receives $95 \%$ of prescribed dose. In each session, patients position check was performed using ExacTrac (Brain Lab) system and cone beam computer tomography (CBCT).

\section{Chemotherapy}

All patients received TMZ concurrently with HFRT. TMZ was administered orally, once daily, at $75 \mathrm{mg} / \mathrm{m} 2$, starting on the first day of HFRT and continuing for the whole treatment. After a 4-week break adjuvant TMZ was administered at 150 to $200 \mathrm{mg} / \mathrm{m}^{2}$ orally, once daily, for 5 consecutive days every 28 days up to 12 cycles, or until disease progression occurred.

\section{Supportive care}

Corticosteroids were administered during the whole HFRT treatment and progressively reduced at the end of RT. Antiepileptic drugs (AEDs) were prescribed only in patients with a history of at least one seizure. The most frequently used AEDs were levetiracetam as first line instance followed by topiramate, lamotrigine or lacosamide.

\section{Evaluation of clinical outcome}

Clinical outcome was evaluated by neurological examination and MRI imaging 1 months after concurrent CHT-HFRT and every four months thereafter. [11C] MET-PET was performed at four and 12 months during maintenance CHT or to rule out pseudo-progression. When needed tumor progression was defined according to Response Assessment in Neuro-Oncology (RANO) working group [27]. Thirty-days postoperative morbidity and mortality were assessed. Major complications were defined as the appearance of new neurological deficits persisting for more than 30 days after surgery and requiring a prolonged hospitalization or rehabilitation. All other complications were defined as minor. The appearance of new deficits or the worsening of preoperative deficits 
were considered as complications. Hematologic and non-hematologic toxicities, including radionecrosis, were graded according to Common Terminology Criteria for Adverse Events version 3.0. Neuropsychological assessment was performed through a shortened version of the "Milano Bicocca Battery", evaluating language, memory, apraxia, visuo-constructional abilities, attentive and executive functions [28]. The total time of administration was one hour on average. Patients were evaluated one week before the start of HFRT (T0), 1 (T1), 6 (T2) and 12 months (T3) thereafter or until disease progression.

\section{Statistical analysis}

The study was designed to demonstrate, with $90 \%$ power and 1 sided $\alpha$ error of 5\%, a significant difference between a reference value of 1 year survival of $55.2 \%$ in standard treatments compared to a figure of $71.4 \%$ for the new one. Variables considered were: gender, age, KPS status, RPA class, EOR and MGMT methylated status. Age of patients was divided into two groups, respectively, $\leq 60$ and $>60$ years. Survival and recurrence time observations were evaluated according to the method of Kaplan and Meier, starting from the date of diagnosis. The median survival time is evaluated obtained from $\hat{S}(t)$, the Kaplan -Meier product-limit estimate of the survivor function. Confidence bounds of the survivor function are calculated based on the asymptotic variance of $\ln [-\ln$ $\hat{\mathrm{S}}(\mathrm{t})$, as described in Kalbfleisch and Prentice. The upper (lower) confidence limits for the median survival times are defined as the first time at which the upper (lower) confidence limit for $\hat{\mathrm{S}}(\mathrm{t})$ is less than or equal to 0.5 . A not reached indicator ( $\mathrm{nr}$ ) was specified if the survival estimate resulted above the $50 \%$ level in the considered observation time. Upper confidence bound of median survival time was labeled as ne if not evaluable with the above method for a specific group of patients in the considered time of observation. In order to assess the prognostic role of the different individual variables, the log-rank test was used for dichotomous variables gender, MGMT and age (grouped). Univariate cox model was applied for the remaining variables. Multivariate Cox regression model was used as a method to estimate the independent association of our variable set with overall survival. Neurophysiological assessment parameters were preliminarily evaluated for a difference before and after RT. In order to assess the effect of the HFRT on neurocognitive functions a series of nonparametric analyses (Wilcoxon signed-rank test) was performed. P value and the mean of the age- and education-adjusted score for each test and for each time point (T0;T1;T2;T3) was reported. Statistical analysis was performed by the use of the Stata software, version 13.1 (Stata Corp LP, College Station TX USA). Methods and calculation details can also be found in the software refence manual in the stata website (http://www.stata.com/).

\section{Abbreviations}

GBM: glioblastoma multiforme

RT: radiotherapy

CHT: chemotherapy

EOR: estent of resection

TMS: temozolomide

HFRT: hypofractionated radiaton therapy

KPS: Karnofsky performance scale

OS: overall survival

PFS: progression free survival

GTR: gross total resection

RTV: residual tumor volume

STR: subtotal resection

PR: partial resection

MET-PET: methionine PET

FLAIR: Fluid-attenuated inversion recovery

MRI: magnetic resonance imaging

DTI: diffusion tensor imaging

IDH: isocitrate dehydrogenase

MPRAGE: magnetization-prepared rapid gradientecho

11CMETPET: [11C]-Methionine-PET

MGMT: O-6-methylguanine-DNA

methyltransferase

CTV: clinical target volume

PTV: planning target volume

VMAT: volumetric modulated arc therapy

SIB: simultaneous integrated boost

OAR: organ at risk

CBCT: cone beam computed tomography

AED: antiepileptic drugs

RANO: Response Assessment in Neuro-Oncology

RPA: recursive partiotioning analysis

\section{Author contributions}

P. Navarria, F. Pessina coordinated the study and processed the data and supervised the analysis

S. Tomatis, L. Cozzi coordinated the data analysis

A. Chiti, A. Santoro, L. Bello, M. Scorsetti conceived the study and participated to the protocol steering

P. Navarria, F. Pessina, R. Soffietti, M. Grimaldi, E. Lopci, A. Leonetti, A. Casarotti, M. Rossi, A. Ascolese, M. simonelli. S. Marcheselli, E. Clerici contributed to the data collection, patients management and clinical activities

\section{CONFLICTS OF INTEREST}

L. Cozzi acts as Scientific Advisor to Varian Medical Systems and is Clinical Research Scientist at Humanitas Cancer Center. All other co-authors have no conflicts of interest

\section{FUNDING}

None. 


\section{REFERENCES}

1. Stupp R, Mason WP, van den Bent MJ, Weller M, Fisher B, Taphoon M, Belanger K, Brandes A, Marosi C, Bogdahn U, Curschmann J, Janzer R, Ludwin S, et al. Radiotherapy plus concomitant and adjuvant temozolomide for glioblastoma. N Engl J Med. 2005;352:987-996.

2. Stupp R, Hegi ME, Mason WP, van den Bent M, Taphoon M, Janzer R, Ludwin S, Allgeier A, Fisher B, Belanger K, Hau P, Brandes A, Gijtenbeek J, et al. Effects of radiotherapy with concomitant and adjuvant temozolomide versus radiotherapy alone on survival in glioblastoma in a randomised phase III study: 5-year analysis of the EORTCNCIC trial. Lancet Oncol. 2009; 10:459-466.

3. Keles GE, Anderson B, Berger MS. The effect of extent of resection on time to tumor progression and survival in patients with glioblastoma multiforme of the cerebral hemisphere. Surg Neurol. 1999;52:371-379.

4. Sanai N, Polley MY, McDermott MW, Parsa A, Berger M. An extent of resection threshold for newly diagnosed glioblastomas. J Neurosurg. 2011;115:3-8.

5. Tsien C, Moughan J, Michalski JM, Gilbert M, Purdy J, Simpson J, Kresel J, Curran W, Diaz A, Mehta M. Phase I three-dimensional conformal radiation dose escalation study in newly diagnosed glioblastoma: radiation therapy oncology group trial 98-03. Int J Radiat Oncol Biol Phys. 2009;73:699-708.

6. Chan JL, Lee SW, Fraass BA, Normolle DP, Greenberg HS, Junck LR, Gebarski SS, Sandler HM. Survival and failure patterns of high-grade gliomas after three-dimensional conformal radiotherapy. J Clin Oncol. 2002;20:1635-1642.

7. Nakagawa K, Aoki Y, Fujimaki T, Tago M, Terahara A, Karasawa K, Sakata K, Sasaki Y, Matsutani M, Akanuma A. High-dose conformal radiotherapy influenced the pattern of failure but did not improve survival in glioblastoma multiforme. Int J Radiat Oncol Biol Phys. 1998;40:1141-1149.

8. Nieder C, Mehta MP. Advances in translational research provide a rationale for clinical re-evaluation of highdose radiotherapy for glioblastoma. Med Hypotheses. 2011;76:410-413.

9. Tanaka M, Ino Y, Nakagawa K, Tago M, Todo T. High-dose conformal radiotherapy for supratentorial malignant glioma: a historical comparison. Lancet Oncol. 2005;6:953-960.

10. Watkins JM, Marshall DT, Patel S, Giglio P, Herrin A, Garrett-Mayer E, Jenrette J. High-dose radiotherapy to 78 Gy with or without temozolomide for high grade gliomas. J Neurooncol. 2009;93:343-348.

11. Malmström A, Grønberg BH, Marosi C, Stupp R, Frappaz D, Schultz H, Abacioglu U, Tavelin B, Lhermitte B, Hegi M, Rosell J, Henriksson R. Temozolomide versus standard 6-week radiotherapy versus hypofractionated radiotherapy in patients older than 60 years with glioblastoma: the Nordic randomised, phase 3 trial. Lancet Oncol. 2012;13:916-926.
12. Roa W, Brasher PM, Bauman G, Anthes M, Bruera E, Chan A, Fisher B, Fulton D, Gulavita S, Hao C, Husain S, Murtha A, Petru K, et al. Abbreviated course of radiation therapy in older patients with glioblastoma multiforme: a prospective randomized clinical trial. J Clin Oncol. 2004;22:1583-1588.

13. Wick W, Platten M, Meisner C, Felsberg J, Tabatabai G, Simon M, Mikkhah G, Papsdorf K, Steinbach J, Sabel M, Combs S, Vesper J, Braun C, et al. Temozolomide chemotherapy alone versus radiotherapy alone for malignant astrocytoma in the elderly: the NOA-08 randomised, phase 3 trial. Lancet Oncol. 2012;13:707-715.

14. Chen C, Damek D, Gaspar LE, Waziri K, KleinschmidtDeMasters B, Robischorn M, Stuhr K, Rusthoven K, Kavanagh B. Phase I trial of hypofractionated intensitymodulated radiotherapy with temozolomide chemotherapy for patients with newly diagnosed glioblastoma multiforme. Int J Radiat Oncol Biol Phys. 2011;81:1066-1074.

15. Reddy K, Damek D, Gaspar LE, Ney D, WAziri A, Lillehei K, Stuhr K, Kavanagh B, Chen C. Phase II trial of hypofractionated IMRT with temozolomide for patients with newly diagnosed glioblastoma multiforme. Int J Radiat Oncol Biol Phys. 2012;84:655-660.

16. Terasaki M, Eto T, Nakashima S, Okada Y, Ogo E, Sugita Y, Tokutomi T, Shigemori M. A pilot study of hypofractionated radiation therapy with temozolomide for adults with glioblastoma multiforme. J Neurooncol. 2011;102:247-253.

17. Jastaniyah N, Murtha A, Pervez N, Le D, Roa W, Patel S, Mackenzie M, Fulton D, Field C, Ghosh S, Fallone G, Abdulkarim B. Phase I study of hypofractionated intensity modulated radiation therapy with concurrent and adjuvant temozolomide in patients with glioblastoma multiforme. Radiat Oncol. 2013; 8:38.

18. Iuchi T, Hatano K, Kodama T, Sakaida T, Yokoi S, Kawasaki K, Hasegawa Y, Hara R. Phase 2 trial of hypofractionated high-dose intensity modulated radiation therapy with concurrent and adjuvant temozolomide for newly diagnosed glioblastoma. Int J Radiation Oncol Biol Phys. 2014; 88:793-800.

19. Walker MD, Strike TA, Sheline GE. An analysis of doseeffect relationship in the radiotherapy of malignant gliomas. Int J Radiat Oncol Biol Phys. 1979;5:1725-1731.

20. Budach W, Gioioso D, Taghian A, Stuschke M, Suit M. Repopulation capacity during fractionated irradiation of squamous cell carcinomas and glioblastomas in vitro. Int $\mathrm{J}$ Radiat Oncol Biol Phys. 1997;39:743-750.

21. Ruben JD, Dally M, Bailey M, Smith R, McLean C, Fedele P. Cerebral radiation necrosis: incidence, outcomes, and risk factors with emphasis on radiation parameters and chemotherapy. Int J Radiat Oncol Biol Phys. 2006;65:499-508.

22. Rusthoven KE, Olsen C, Franklin W, KleinschmidtDeMasters B, Kavanagh B, Gaspar L, Lillehei K, Waziri A, Damek D, Chen Cl. Favorable prognosis in patients with high-grade glioma with radiation necrosis: the University of 
Colorado reoperation series. Int J Radiat Oncol Biol Phys. 2011;81:211-217.

23. Chaichana KL, Jusue-Torres L, Navarro-Ramirez R, Raza S, Pascual-Gallego M, Ibrahim A, Hernandez-Hermann M, Gomez L, Ye X, Weingart J, Olivi A, Blakely J, Gallia G, et al. Establishing percent resection and residual volume thresholds affecting survival and recurrence for patients with newly diagnosed intracranial glioblastoma. Neuro Oncol. 2014;16:113-122.

24. McGirt MJ, Chaichana KL, Gathinji M, Attenello FJ, Than K, Olivi A, Weingart JD, Brem H, Quiñones-Hinojosa AR. Independent association of extent of resection with survival in patients with malignant brain astrocytoma. J Neurosurg. 2009; 110:156-162.

25. Castellano A, Bello L, Michelozzi C, Gallucci M, Fava E, Iadanza A, Riva M, Casaceli G, Falini A. Role of diffusion tensor magnetic resonance tractography in predicting the extent of resection in glioma surgery. Neuro Oncol. 2012;14:192-202.

26. Wick W, Weller M, van den Bent M, Sanson M, Weiler M, von Deimling A, Plass C, Hegi M, Platten M, Reifenberger G. MGMT testing--the challenges for biomarker-based glioma treatment. Nat Rev Neurol. 2014;10:372-385.

27. Wen PY, Macdonald DR, Reardon DA, Cloughesy T, Sorensen A, Galanis E, Degroot J, Wick W, Gilbert M, Lassman A, Tsien C, Mikkelsen T, Wong E, et al. Updated response assessment criteria for high-grade gliomas: response assessment in neuro-oncology working group. J Clin Oncol. 2010;28:1963-1972.

28. Papagno C, Casarotti A, Comi A, Gallucci M, Riva M, Bello L. Measuring clinical outcomes in neuro-oncology. A battery of evaluate low-grade glioma (LGG). J Neurooncol. 2012;108:269-275. 